\title{
Phylogenetic Analysis and Assessment of the Pathogenic Potential of Avian Influenza Virus H9N2 in Wild Waterfowl, Wild Birds, and Lagoon Water in Tunisia
}

IMEN LARBI ( $\square$ imen.larbi@pasteur.tn )

Institut Pasteur de Tunis https://orcid.org/0000-0002-6588-2361

Kais Ghedira

Institut Pasteur de Tunis

Gary D Butcher

University of Florida College of Veterinary Medicine

Natalia Rego

Institut Pasteur Montevideo

Marwa Arbi

Institut Pasteur de Tunis

Hugo Naya

Institut Pasteur Montevideo, Facultad de Agronomia Universidad de la Republica Departmento de Produccion Animal y Pasturas

Halima Tougorti

Institut Pasteur de Tunis

Imen El Behi

Institut Pasteur de Tunis

Jihene Nsiri

Institut Pasteur de Tunis

Jihene Lachheb

Institut Pasteur de Tunis

Abdeljelil Ghram

Institut Pasteur de Tunis

Research Article

Keywords: H9N2, avian influenza viruses (AIV), Himantopus himantopus, Chroicocephalus crirrocephalus, Phoenicopterus roseus

Posted Date: May 5th, 2021

DOI: https://doi.org/10.21203/rs.3.rs-482794/v1

License: (c) (i) This work is licensed under a Creative Commons Attribution 4.0 International License. Read Full License 


\section{Abstract}

H9N2 avian influenza viruses (AIV) have been isolated from various species of wild birds and domestic poultry worldwide. They have been described to not only infect mammals directly, but also provide gene segments to generate novel but lethal human reassortants. H9N2 AIV has circulated in Tunisian commercial poultry since 2009 and poses a serious threat to the poultry industry. In the present study, we investigate five H9N2 viruses isolated from greater flamingoes (GF) (Phoenicopterus roseus), gray-headed gull (GHG) (Chroicocephalus crirrocephalus), black-winged stilt (BWS) (Himantopus himantopus), and lagoon water (EN) from Maamoura Lagoon, Korba Lagoon, and Kuriat Island in Tunisia from 2014-2018. Full-length genome sequences of AIV H9N2.Viral sequence analyses showed several amino acid changes related to viral adaptation to mammals. Phylogenetic analyses demonstrated that the five isolates belonged to the same sublineage G1and were close to AIV H9N2 poultry strains isolated in North Africa, West Africa, and the Middle East. At the hemagglutinin (HA) cleavage site, viruses (GF/120/15), (BSW/119/18), (GHG/216/18), and (EN/117/18) had the 335RSSR/GLF341 motif. However, (GF/121/14) undergo punctual substitutions at the HA1/HA2genesand acquires the dibasic pattern 335KSSR/GLF341.All Tunisian viruses carried in their hemagglutinins the humanlike marker 226L, which is important for avian-to-human viral transmission. The neuraminidase (NA) of the five viruses showed S372A and R403W substitutions previously detected in H9N2 from Asia and the Middle East and in H3N2 and H2N2 strains reported in human pandemics. Many mutations associated with mammalian infections have been detected in internal proteins. Chicken experiments (IPIV) show that the five Tunisian viruses displayed low pathogenicity, causing mild symptoms in chickens. The virus could not kill mice, and merely replicated when administrated to mice. To our knowledge, this is the first study to address the evolution, pathogenicity, and transmission of the H9N2 viruses isolated from wild birds, waterfowl, and lagoon water in North Africa. Our results indicate that we should pay greater attention to H9N2 AIV surveillance in wilds birds. These results provide new insights into the measures that need to be undertaken regarding the role of wild birds in AIV introduction and persistence in Tunisia.

\section{Introduction}

Wild waterfowl and sea birds are the natural hosts of influenza viruses, except $\mathrm{H} 17 \mathrm{~N} 10$ and $\mathrm{H} 18 \mathrm{~N} 11$, which have only been found in bats [40]. Low pathogenicity avian influenza virus (LPAIV) subtype H9N2 is the most prevalent LPAIV in poultry, worldwide [16]. During the last decades, H9N2 AIVs have been circulating widely in the poultry population and became endemic in poultry farms across Asia, the Middle East and North and West Africa, causing tremendous losses [13]. In Tunisia, H9N2 was isolated for the first time in 2009 from industrial poultry [37].

North Africa regions represent spring migration areas for birds. Every year, hundreds of thousands of wintering birds from subSaharan Africa head for their breeding grounds. Tens of thousands of waterfowls (Anseriformes and Charadriiformes) gather in the wetlands of North Africa from March to May, along with the Afro-tropical water birds that remained in North Africa throughout the year [28].

The North African wetlands can, therefore, constitute ecosystems for the perpetuation of AIV during the spring, a period when AIV is rare in spring water birds in Europe, and also for the emergence of new AIV through re-assortment between various strains of AIV brought from different geographical origins [28].

In Tunisia, in August 2014-2015 at the Korba Lagoon, greater flamingo samples were taken from healthy birds as part of surveillance during the first breeding attempt at this site. The Korba Lagoon is the only permanent water along the eastern coast of Cap Bon and offers a valuable habitat for breeding water birds or migratory birds. The site is the most crowded among Peninsula wetlands during the major phonological stages. In 2018, we reported the death of 200 wild birds (gray-headed gulls, black-winged stilt) at Maamoura Lagoon in April and at Kuriat Island in August, respectively, in northern and central Tunisia.

There have been outbreaks of the A/H9N2 avian influenza in aquatic birds. Indeed, greater flamingo (Phoenicopterus roseus), grayheaded gulls (Chroicocephalus crirrocephalus), and black-winged stilt (Himantopus himantopus) can contaminate the natural water bodies that inhabit and can spread to the Tunisian territory. Great numbers of migratory birds spend the summer and spring on Maamora Lagoon, Korba Lagoon, and Kuriat Island, and an epidemic of bird flu would likely kill more than 200 birds.

This is the first outbreak that has caused high mortality among wild waterfowl and wild birds, in Tunisia. Various aquatic species might promote the persistence and transmission of AIV; however, studies related to the role of aquatic fauna in the persistence and 
transmission of avian influenza virus are scarce. Consequently, characterization of H9N2 viruses derived from wild waterfowl and wild birds will increase our understanding of this epidemic pathogen, and could potentially contribute positively, to the prevention and control of H9N2 AIVs in Tunisia. Moreover, there is limited knowledge about the genetic characteristics and biological properties of the H9N2 influenza virus isolated from greater flamingo, gray-headed gull, black-winged stilt, and lagoon water.

In the present study, we have characterized the sequences, pathogenicity, and transmissibility of H9N2 strains isolated from greater flamingo, gray-headed gull, black-winged stilts, and lagoon water in Tunisia.

\section{Materials And Methods}

\section{Ethics Statement}

All animal experiments were approved by the Ethics Committee of the Institut Pasteur de Tunis. For the biological facility, all experiments with live H9N2 viruses were conducted within the enhanced animal. All experiments involving live viruses and animals were carried out in biosafety level 2+ laboratory (ABSL2+) facilities in Institut Pasteur de Tunis. HEPA-filtered animal isolators were used.

\section{Surveillance site and specimen collection}

Specimen collection was conducted in Korba Lagoon and Mammoura Lagoon, which are located in the North of Tunisia, and on Kuriat Island, which is located in the Center of Tunisia. These three sites are included in the Ramsar Wheatland. Organ samples inclunding (trachea, lungs, intestine, spleen, kidney, brain, liver and heart) from dead birds (gray-headed gulls and black-winged stilts) and lagoon water were collected, cloacae and tracheal swabs were also taken from greater flamingo and suspended in $2 \mathrm{ml}$ of phosphate-buffered saline (PBS) supplemented by 10,000 units $/ \mathrm{ml}$ penicillin, $10 \mathrm{mg} / \mathrm{ml}$ streptomycin sulfate, and0.3 $\mathrm{mg} / \mathrm{ml}$ gentamicin sulfate (Table1).

\section{Virus isolation}

The viruses were propagated in 9 to 11 day-old embryonated SPF chicken eggs via allantoic sac inoculation. Allantoic fluids were collected and centrifuged on a sucrose gradient at 240,000 $\times \mathrm{g}$ for $2 \mathrm{~h}$. The collected fluids were tested for the presence of hemagglutinating viruses by haemagglutination test $(\mathrm{HA})$ using $1 \%$ chicken erythrocyte suspension. The HA-positive samples were identified serologically using specific anti-AIV antisera, as described previously. H9N2 virus-containing allantoic fluids were tested for viral RNA extraction and the animal experiments. The $50 \%$ egg infectious dose (EID50) was determined by serial dilutions of the virus in to embryonated eggs, and the value was calculated using the method described by Reed and Muench [24].

\section{Molecular detection and characterization}

\section{Real-time RT-PCR for IA typing and subtyping}

Viral RNA was extracted from allantoic fluid with RNAisoPlus. The samples were analyzed by real-time reverse transcriptasepolymerase chain reaction (RT-PCR) using a One-Step Qiagen RT-PCR kit (Qiagen) with primers and probes targeting the conserved region of the matrix $\mathrm{M}$ ) gene. AIV positive samples were then tested for $\mathrm{H} 9$ subtypes following the described protocols. Samples with threshold $(\mathrm{Ct})$ values $\leq 35$ were considered positive [20].

The assay was performed under the following conditions: a reverse transcription phase for $30 \mathrm{~min}$ at $50^{\circ} \mathrm{C}$ and 15 min at $94^{\circ} \mathrm{C}$, followed by PCR reactions of 40 cycles with $45 \mathrm{~s}$ at $94^{\circ} \mathrm{C}$, and 45 sat $54^{\circ} \mathrm{C}$. Data provided by the thermocycler were analyzed and processed by the Swift software.

\section{MRT-PCR of the whole genome}

MRT-PCR efficiently amplifies the genome of any subtype of human or animal lineage influenza A virus. v RNA isolated from $100 \mu \mathrm{l}$ of culture supernatant or allantoic fluids served as a template for a RT-PCR with $0.2 \mu \mathrm{M}$ of MBTuni- 12 and MBTuni-13, performed using the Super Script II one-step RTPCR system (Invitrogen). The protocol was used as described previously by Bin Zhou et al. For amplification, all of the vRNAs were designed to take advantage of the conserved vRNA termini and were 5 ' tailed. The temperature 
cycle parameters were $45^{\circ} \mathrm{C}$ for $60 \mathrm{~min}, 94^{\circ} \mathrm{C}$ for $2 \mathrm{~min}$, and then five cycles $\left(94^{\circ} \mathrm{C}\right.$ for $30 \mathrm{~s}, 45^{\circ} \mathrm{C}$ for $30 \mathrm{~s}$, and $68^{\circ} \mathrm{C}$ for $3 \mathrm{~min}$ ), followed by 35 cycles $\left(94^{\circ} \mathrm{C}\right.$ for $30 \mathrm{~s}, 57^{\circ} \mathrm{C}$ for $30 \mathrm{~s}$, and $68^{\circ} \mathrm{C}$ for $30 \mathrm{~min}$ ), with a final cycle of $68^{\circ} \mathrm{C}$ for $10 \mathrm{~min}$.

\section{Genome sequencing (NGS)}

NGS sequencing was conducted, using multiplexed Illumina MiSeq technology. Initially, the cDNA samples were fragmented using an ultrasonication approach (Covaris). Resulting DNA fragments with sizes ranging from 300-800bpwere selected using AMPure XP beads. These fragments were then end-repaired, and Illumina-specific adapter sequences were ligated to each fragment.

Each sample has been individually indexed, and a second size selection step was performed. Samples were then quantified using a fluorometric method, diluted to a standard concentration ( $4 \mathrm{nM})$, and then sequenced on Illumina's MiSeq platform, using a MiSeq v3 (600 cycles) kit, following a standard protocol as described by the manufacturer. About 200MB of data $(2 \times 300 \mathrm{bp}$ paired-end reads) was produced for each sample. The de novo and directed assembly of genome sequences was performed using the Genome detective tool. The reads were mapped to other AIV viruses.

\section{Phylogenetic and genotypic analysis}

The nucleotide sequences of all eight genome segments determined in this study were compared to the H9N2 sequence data available in the NCBI database using the Bioedit 7.2.6 program, and the phylogenetic relationship was established. All of the sequences were aligned using the 'CLUSTALW' program (http://clustalw.genome.ad.jp). Phylogenetic trees were generated using the distance-based maximum likelihood method with MEGA software (version 6.06).

\section{Animal manipulation}

All animal studies have been approved by the Institut Pasteur de Tunis (IPT), the Laboratory Animal Administration Committee, and were done in accordance with the guidelines of the Animal Welfare and Ethics laboratory.

\section{Chicken intravenous pathogenicity tests}

The intravenous pathogenicity index (IVPI) was determined as recommended by the OIE [27]. Four H9N2 viruses (GF/TN/120/15, GF/TN/121/14, GHG/TN/216/2018 and BWS/TN/119/18) were selected for pathogenicity, based on their species, phylogenic relationships. Six-week-old SPF white leghorn chickens (five per group) were intravenously inoculated with $0.1 \mathrm{ml}$ of 1:10 dilution of viral suspensions, and the control group was inoculated with PBS. Clinical signs of disease were observed for 10 days, and the (IVPI) were calculated, according to the OIE recommendation [27].

\section{Mouse experiments}

To compare the virulence of the four isolates (GF/TN/120/15), (GF/TN/121/14), (GHG/TN/216/2018), and (BWS/TN/119/18). Sixto eight-week-old BALB/c female mice were inoculated intranasally with the following doses: $10^{8.75} 50 \%$ egg infectious doses (EID50), $10^{7} \mathrm{EID} 50,10^{7.5} \mathrm{EID} 50,10^{7,5} \mathrm{EID} 50$ of viruses in $50 \mu \mathrm{l}$ (PBS), respectively. All mice were weighed before inoculation. Three naïve mice were added to each infected group to serve as transmission controls. The control group consisted of five mice, which were inoculated with the same volume of PBS. All animals were weighed individually and monitored for signs of illness and mortality for 14 days. Three mice from each group were euthanized on days 3, 6, 8, 10, and 14 post-infection, and samples of nasal turbinate, trachea, lungs, brains, kidneys, spleens, hearts, and livers were collected for virus titration and post-mortem analyses. Organ samples were homogenized in $1 \mathrm{ml}$ PBS buffer and centrifuged $10 \mathrm{~min}$ at $8000 \mathrm{rpm}$. The RNA was extracted from the organ suspension as described above. A real-time RT-PCR test targeting the AIV-M and H9 gene was performed.

\section{Result}

\section{Pathogenicity in chicken}

The IVPI values were 0.53 for (GF/TN/120/15), 0.50 for (GF/TN/121/14), 0.52 for the (GHG/TN/216/18), and 0.54 for (BWS/TN/119/18). The virus was detected using a real-time RT-PCR test targeting the IAV M and H9 genes in the trachea, lung, spleen, and heart of chicken euthanized at3and 6days post-infection (dpi). The chickens infected with AIV (GF/TN/120/15), 
(GHG/TN/216/18), and (BWS/TN/119/18) showed mild clinical signs from 3dpi until 6 dpi. Chicken infected with (GF/TN/121/14) revealed average clinical signs. The clinical signs included: dyspnea and nasal discharge. No fatalities weight losses were observed.

\section{Pathogenicity in mice}

To test the pathogenicity of the low pathogenic H9N2 isolates in a mammal model, four groups of mice were inoculated with AIV (GF/TN/120/15), (GF/TN/121/14),(GHG/TN/216/18), and (BWS/TN/119/18) virus. The four groups of mice showed a slight loss of body weight at $8 \mathrm{dpi}$, and then gradually gained bodyweight (Fig 1). No obvious signs were present, except the loss of weight and all the mice survived the experiment. In a post-mortem analysis, edema of the kidneys and lungs was observed in two mice inoculated with (GF/TN/121/14). Nasal turbinate, trachea, and lungs showed the infectivity and replication ability of the four isolates in mice in $3 \mathrm{dpi}$ until $8 \mathrm{dpi}$, based on real-time RT-PCR results targeting the IAV M and H9 genes (Table 1). The virus was not detected in the livers, hearts, spleens, intestines, kidneys, and brains of the inoculated mice. The naïve mice, placed in the same cage as the infected mice, also showed infectivity and replication. This demonstrates that the virus is able to spread from one mouse to another. This result indicates that the four viruses could infect and replicate in mouse lungs without prior adaptation.

\section{Phylogenetic analysis of the five H9N2 viruses}

To determine the evolutionary relationships between Tunisian H9N2 isolates and those selected in Genbank, phylogenetic analyzes were performed for the eight viral gene segments (the two surface glycoprotein genes HA and NA; the seven internal structural proteins M1, M2, NP, PA, PB1, PB2, and NS2; and the non-structural protein NS1). The nucleotide sequences are available from GenBank under the accession numbers: MW375771-MW375778 ; MW375808-MW375815 ; MW356853-MW356860 ; MT607623MT607630 ; MT609882-MT609889.

The phylogenetic relationships of the five H9N2 Tunisian isolates were compared with other available sequences obtained from the NCBI Influenza Virus Resource. The phylogenetic analysis showed that the five isolates belonged to the same G1 sub-lineage (A/Quail/Hong Kong/G1/1997) in all eight gene segments, reflecting the low pathogenic H9N2 AIVs circulating in wild waterfowl and migratory birds. Several studies have revealed that H9N2-G1-like viruses have the potential for replication in epithelial human and mouse cell cultures. Thus, these strains could become human pathogen via pigs or avian species, or through a direct adaptation in humans [38]. The BLAST results against the GenBank database show that the isolates had high homology with the H9N2 viruses circulating in the Middle East. The nucleotide sequence identity of isolates ranged from $95-98 \%$ for the eight genes.

\section{The HA and NA genes}

The phylogenetic analysis of HA and NA genes showed that four Tunisian strains [(GF/TN/121/14), (GF/TN/120/15), (BSW/TN/119/18), and (GHG/TN/216/18)] were closely related to each other, with nucleotide identity of $98.97 \%$ and $99 \%$ for HA and NA, respectively. However, strain (EN/TN/117/18) exhibited the lowest percentage identity (91.75-90.3\%) for HA and NA, respectively, as compared to the four H9N2 viruses. Also, the four cited H9N2 strains were closely related to Tunisian chicken AIV H9N2 identified previously $2010-2016$ (similarities of $96.32 \%$ to $99.06 \%$ and 97.73 to $100 \%$ for the HA and NA genes, respectively $[1,38]$. Strain (EN/TN/117/18) showed a low percentage similarity to previous isolated Tunisian chicken AIV H9N2 for the HA (91\%, $67-91 \%, 90 \%)$ and NA $(91.41 \% 90.84 \%)$ genes $[1,37]$.

The wild bird and waterfowl AIV H9N2 studied clustered with AIV H9N2 isolated from Libya (2015) [18), with genetic identity values of $97.95 \%$ and $98.51 \%$ for HA and clustered with the United Arab Emirates (UAE) AIV H9N2 with genetic identity (93.54\% to 94.83\%) for NA [36]. The lagoon water AIV strain (EN/TN/117/18) clustered with AIV H9N2 isolated from the different geographic regions: Morocco 2016 [14], Algeria 2017 [3], UAE 2015 [36], Senegal and Burkina Faso 2017 [5] (Fig2).

\section{The PB2, PB1, PA, NP, M, and NS genes}

Phylogenetic analysis of the six internal genes (PB2, PB1, PA, NP, M, and NS) of the five studied Tunisian H9N2 strains belonged to the G1 sub-lineage and were related to each other with nucleotide identities of $96-97 \%, 96-98 \%, 99-100 \%, 94-97 \%$, 95-99\%, 94$99 \mathrm{M} \%$ for the PB2, PB1, PA, NP, M, and NS genes, respectively, with no re-assortment event. Strain (EN/TN/117/18) remained the most distinct strain. The five AIV H9N2 strains isolated from wilds birds, waterfowl, and environment shared nucleotide sequence 
identity with chicken Tunisian AIV H9N2 strains isolated previously $(2010-2016)[1,38]$ with percentage identity values of $94 \%, 94 \%$, 92-93\%, 94\%, 95\%, and $97-98 \%$ for PB2, PB1, PA, NP, M, and NS, respectively.

The PB2, PB1, PA, NP, M, and NS genes of (GF/TN/120/15), (GF/TN/121/14), (GHG/TN/216/18), and (BSW/TN/119/18) showed high nucleotide identities and phylogenetic relationship with those reported in the UAE, and Saudi Arabia, of at least $95.76 \%, 96.98 \%$, $98.76 \%$, and $94.65 \%$, respectively. (EN/TN/117/18) showed high nucleotide identities and a close phylogenetic relationship with AIV H9N2 isolated in Morocco [14], Algeria [3], Togo, Ghana [16], and Burkina Faso [5], already grouped within the G1 sub-lineage.

\section{Molecular characterization of the eight viral segments}

\section{Molecular Characterization of surface genes}

Four Tunisian AIV isolates [(GF/TN/120/15), (BSW/TN/119/18), (GHG/TN/216/18), and (EN/TN/117/18)] lacked a monobasic cleavage site (H9 numbering), which is characteristic of H9N2 viruses with low pathogenicity isolated from the Middle East and Asia and shown to be well adapted to the chicken [9]. These four isolates shared the same HA1/HA2 cleavage site motif (335RSSR/GLF341) (Table3), except for one isolate from greater flamingo (GF/121/14) that exhibited the dibasic pattern at the cleavage site KSSR/GLF motif (in contrast to all previous Tunisian AIV H9N2 isolates) [1].

The glycoprotein HA is a major determinant of host change, mainly because of its role in receptor recognition of the host cell. Two AIV strains (isolated from greater flamingo and lagoon water) had different cleavage site patterns from those isolated from 2010 to 2016 [1]. The strain (GF/TN/121/14) had a lysine (K) residue at position 335, and the strain (EN/TN/117/18) had a Histidine $(\mathrm{H})$ at position 333. The receptor-binding site (RBS) of the Tunisian AIV wild bird and lagoon water H9N2 strains carried the 234L (236L in H3 numbering) and 235I markers [38]. This molecular marker has been observed for the first time in Tunisian AIV in wild waterfowl, wild birds, and AIV environment strains. The five strains showed conservation of residues (P110, W161, T163, H191, A198, and I235) in the receptor-binding pocket for the RBS receptor binding site, with the exception of (GF/TN/120/15) and (GF/TN/121/14) that had the A198T substitution, which has been associated with mammalian tropism of H9N2 viruses [38]. All studied isolates showed seven potential glycosylation sites (PGS), at positions: 29-31 (NST), 105-107 (NGT), 141-143 (NVT), 289-300 (NST), 305-307 (NIS), 492-494 (NGT), and 551-553 (NGS). In addition, strain (EN/TN/117/18) showed another glycosylation site at positions 82-84 (NPS).

The functional activities of NA are influenced by the active site of the HB enzyme, the length of the stem, and the potential glycosylation site. The "HB" site of neuraminidase consists of three loops interacting directly with the sialic acids of cellular receptors. These loops are located at the globular head of neuraminidase in positions 366-373, 399-406, and 431-433 [16].

Although the NA gene sequence was derived over time, the residues defining the H9N2 line were retained, consisting of seven amino acids (L10, T43, S77, S153, T212, V307, and G346).

Neuraminidase for Tunisian isolates was substituted in the HB site, similar to other H9N2 avian viruses isolated from Asia and the Middle East during human H2N2 and H3N2 pandemics that have the ability to bind to the $\mathbf{a}$-receptor $\mathbf{a} 2,6$. Besides, a potential glycosylation site was identified as 402NWS404 for Tunisian isolates, as well as in strains isolated from the Middle East, , thus showing some variations. In the strains isolated in this work, the substitution of W to S occurred and led to the emergence of a new site of glycosylation 331NSS334 that was previously found in the strain (A/Chicken/Jordan/1540/2003(H9N2)). The 431PKE433 glycosylation site was previously identified in strain (A/Ck/HK/G9/97) [37].

The NA protein also revealed mutations in amino acid residues out of three loops that interact directly with sialic acid. On the loops carrying the amino acids 367-370-372, the three Ser (S) were substituted with KLA. Furthermore, D and Y substitutions were found at residues 401 and 406, respectively [37]. The R371, A372, N402, and E425 amino acid substitutions were detected at the framework site. Also, the amino acid sequence of the NA protein shows the presence of residues L370, I392, and I427, which provide the ability for H9N2 viruses to replicate in mouse cells without killing them [19). We observed the D198N, T72K, F409N, D411Y, I414 V, R432O, E430K/R, and A435V substitution, which have been reported in the Genbank database. Their functions remain unknown and might affect virulence, pathogenicity, and host specificity.

\section{Molecular characterization of internal genes}


Amino acid residues in the polymerase proteins (PB1, PB2, and PA) and in the nucleoprotein (NP) are known to play a major role in increasing virulence and replication in mammalian hosts, whereas others might influence the efficiency of replication in mammalian or avian hosts [16].

The PB1 of wild waterfowl, wild birds, and Lagoon Water of Tunisian H9N2 strains showed conserved residues 13P, 207K, and 436Y that are associated with adaptation to AIV mammals [11]. Also, Tunisian PB1 isolates revealed some amino acids important for host pathogenicity and virulence, which are 538D, 578K, and 678S [25]. The cap-binding region of the PB2 protein had conserved residues E249 for two strain (GF/TN/121/14) and (BWS/TN/119/18) other strains had point mutation; E249D for (EN/TN/117/18) and (GHG/TN/216/18), reported for the first time, and E249A for strain (GF/TN/120/15). The (GF/TN/120/15) exhibited R251K substitution, which is reported to increase viral replication and pathogenicity of H1N1 viruses [22].

The nucleoprotein NP allows the encapsidation of the viral genome to form a ribonucleoprotein particle ready for transcription and packaging. This protein interacts with other vial proteins (PB1, PB2 and M1) and certain cellular proteins (such Importin a, F-actin...) to ensure viral transcription and control of nuclear transport. Tunisian studied strains showed conserved residues that define the G1 lineage: R422, K430, T442, D455 and D480 [37]. Interestingly, the NP protein revealed an E372D substitution only in strain (BWS/TN/119/18) and (GHG/TN/216/18) commonly observed in human-associated H9N2 viruses [35]. The PA protein sequences of our isolates have a similarity percentage ranging from 94.18 up to $99.66 \%$ with the selected strains in the Genbank database. The PA protein of wild waterfowl, wild birds and Lagoon Water showed mutation S409N that have been reported in highly pathogenic AIVs (H1N1pdm09, H7N9 novel, H2N2, H5N1, H3N2) [17,32) that enhance the fitness of the virus in humans. We also observed a new substitution on PA protein of Tunisian strains K262R on three strains (LW/TN/117/18), (BWS/TN/119/18) (GHG/TN/216/18), and R391K reported on (GF/TN/120/15) and (GF/TN/121/14) these substitutions had been found in H1N1, H7N9. The amino acids of (GF/TN/120/15) and (GF/TN/121/14) were characterized by the appearance of mutations I407V, which is characteristic of H1N1are also rare in other avian influenza viruses [17], associated with mammals, specifically, residues that are important for changing the range of avian to humans hosts. In contrast, isolated strains were found to contain virulent L672 and L550-associated substitutions. Besides molecular characterization analysis of non-structural protein NS, our isolates do not have the deletion of the four amino acids (80TIAS84), with a protein of 230 amino acids in length, containing a "C-terminal" motif of PDZ ligand (PL) 227GSEV230 with the absence of the D92E mutation required for high virulence [37). The motif "GSEV" was previously reported in the Middle East, Dubai in 2001 and 2003 (unpublished data) and confirmed by Shaw et al. and Pan et al. that it supports viral replication in mammals [32,29].

In the NS1 RNA binding domain, all Tunisian isolates conserve R38 and K41 that were reported in strain A/Ck/TUN/12/2010, two motifs considered critical for RNA binding as well as the amino acids P31, D34, R35, G45, R46, and T49, which also participate in the NS1-dsRNA interaction. Also, it has been shown that the substitution D55E of NS1 is related to the virulence of the H5N1 strain in mammals and the resistance to cytokines; such a mutation was found in all Tunisian isolated strains. Nevertheless, their effectors domain carries Leu at position 103 and Gly at position 184. In fact, the F103L mutation is an adaptive genetic determinant of growth and virulence in humans of the avian NS1 gene. Similarity, it has been shown that, addition to its contribution to cleavage and binding to the specific polyadenylation factor, G184 strongly influences viral virulence by an unknown mechanism that does not involve the INF system [33]. Also, all the Tunisian viruses on NS1 protein contain a serine in position 42 and alanine in position 149. In recent studies using strains from ostriches in China, these two motifs would found to participate in the increased virulence in mammals [9]. Other substitutions were detected for the first time in Tunisian viruses and have not been previously reported in other studies; R67Q, E71K, R100K, I129V, V136I, with two other mutations in strains (BWS/TN/119/18), (GF/TN/121/14) and (GF/TN120/15) Q109R, R211G. It would be interesting to evaluate the impact of these mutations on the virulence of H9N2 strains isolated from waterfowl.

Amino acids in the M1 and M2 matrix protein are related to viral replication capacity in mammals or increased pathogenicity in mammalian animal models. These amino acids are located at positions15I (M1), 2A (M1), 30D (M1), 215A (M1), and 55F (M2) [7, 9, 32]. Additionally, the A30S (M2) substitutions observed for the first time in wilds birds, waterfowl, and the environmental AIV H9N2s in Tunisia having been described only in South East Asia and North America in the H5 and $\mathrm{H} 7$ subtypes and associated with resistance to the antiviral blocking M2 channel, such as amantadine [9]. All Tunisian AIV H9N2 viruses were characterized by the conservation of these substitutions. This antiviral binds to the $\mathrm{M} 2$ ion channel region and prevents the release of viral RNA into the cell. Isolated strains harbor two amino acids ( $G 6$ and 18 ) analogous to human viruses that are linked to the ion channel domain, but

Page $7 / 16$ 
the role of these substitutions in mammalian cell replication is not yet known $[7,32,37]$. One Tunisian strain carried new substitutions observed at 224S (M1), for which biological effects are unknown.

\section{Discussion}

Domestic poultry infections, particularly chickens with the H9N2 subtype of the avian influenza virus (AIV), started to be frequently reported in China in the 1990s and other Asian and North American countries.

These viruses have been grouped into different subsets based on antigenic and genetic properties. Although H9N2 viruses do not meet the criteria of highly pathogenic avian influenza, they are unique in this category, infecting a wide variety of species, including chickens [39], quail, pigeons, turkeys, ducks, geese, pigs, and humans. Several studies have reported that G1-type H9N2 viruses can infect humans and can reproduce in human alveolar epithelial cells and the mouse respiratory system. They may emerge as human pathogens, although they are reassorted in intermediate hosts, such as pigs and avian species, or by direct adaptation to humans. In fact, a study conducted by a British team on the African continent revealed that the danger of introducing highly pathogenic avian influenza viruses into the Tunisian territory is associated not only with migratory birds but also with the poultry trade. This report, published in February 2010, considers Tunisia's coastal regions as areas at high risk of infection with highly pathogenic avian influenza viruses [34]. Thus, national and regional trade could be considered as a preponderant factor that is involved in the spread of the disease in Tunisia.

The bird flu virus represents a significant risk, both internationally and nationally, and could present a high economic impact. This characteristic pathology of poultry farms is attributed to a virus having the capacity to cross species barriers, thus being able to infect humans. Since 1997, cases of transmission to humans have been reported; the $H 5, H 7$, and $H 9$ subtypes are potential causes $[26,31]$. For example, the non-glycoprotein genes of human H5N1 and the H9N2 viruses were closely related to each other and different from those of other AIV. The high degree of similarity between avian and human isolates indicates that any specific pressure for replication in humans is minimal. This is expected since patients would most likely have contracted an infection from poultry exposure as there was no evidence of human-human transmission [8].

Tunisia has never reported cases of highly pathogenic H5N1, but the threat is still present due to persistent endemic circulation of the virus in some nearby countries, such as Egypt and Lybia. However, since 2009, AlV subtype H9N2 has become endemic in Tunisia and started causing significant economic losses to the industrial poultry sector. The reasons for the persistence of AIV subtype H9N2 remain unclear due to the absence of large populations of waterfowl that can constitute an aquatic reservoir, as is the case in Asia or in the Nile Valley [10].

Therefore, it is important to actively monitor the evolution of chicken-derived H9N2 in Tunisia. H9N2 AIV strains from wild birds, waterfowl, and the environment are not well characterized in Tunisia. Here we characterized the sequences of H9N2 strains isolated from greater flamingo, gray-headed gull, black-winged stilt, and lagoon water, and evaluated the pathogenicity and transmissibility of avian isolates. These findings might also provide insight into the role of wild birds in AIV H9N2 introduction and persistence in Tunisia.

In Tunisia, wild birds migrate from Eurasia and neighboring countries, such as Libya, that have experienced A/H5N1 outbreaks among their domestic poultry (18]. The Maamoura Lagoon, Korba Lagoon, and Kuriat Island are major flyways for migrant greater flamingo, black-winged stilt, and gull, which stopover during their northern and southern migration and might contribute to the transmission of the AIV disease to poultry farms with low biosecurity measures, especially that the second-largest concentration of Tunisian industrials poultry is to be found in Nabeul governorate, where the Maamoura Lagoon and Korba Lagoon are located.

In this study, phylogenetic analysis showed that the five AIV H9N2 strains isolated from wild birds, waterfowl, and lagoon water belong to the G1 lineage. The eight gene sequences grouped with different Tunisian AIV chicken H9N2 isolated during (2010-2016) and were closely related to AIV H9N2 strains from North Africa [3,14,18], West Africa [2,5], and the Middle East [36]. AIV H9N2 isolated from greater flamingos, gray-headed gull and black-winged stilt during 2014-2018 were closely related to AIV Tunisian H9N2 previously isolated from chicken during (2010-2016). There is a considerable risk that these avian species have been the origin of the introduction of AIV H9N2 in Tunisia, North Africa, and West Africa on their arrival during migration, and that these AIVs transmit partially or completely to bird species linked to residues with a more extensive transmission to local manufacturers or 
domestic birds. Strain (EN/TN/117/18) shared a monophyletic aspect with chicken AIV H9N2 strains from neighboring countries in North Africa, such as Algeria and Morocco $[3,14]$ and also with West Africa, such as Burkina Faso, and Ghana [2,5]. This suggests that wilds birds spread viruses in the region. The population of breeding migratory birds in Tunisia, which is the stopping site of much of the migratory bird population, is diverse, and when they leave the breeding site for the wintering sites, they potentially spread viruses to other countries. The limited migratory bird influenza virus sequence data available from North African, West African, and Middle-Eastern countries makes it difficult to identify the origin of our H9N2 isolates. The similarities between our viruses and those from the Middle East confirm that the viruses isolated from these outbreaks are the likely direct progenitors of those circulating in the Middle East.

Sequence analysis showed the five viruses carried four amino acid sequences at the cleavage site: PSRSSR/GLF for (GF/TN/120/15), PARSSR/GLF for (GHG/TN/216/18) and (BWS/TN/119/18), HARSSR/GLF for (EN/TN/117/18), and PSKSSR/GLF for (GF/TN/121/14). This is typical for low- pathogenic AIV and was confirmed by the chicken intravenous pathogenic test. The five viruses presented many mammalian-adaptative substitutions. Particularly, the hemagglutinin human-like marker 234L (226 in H3 numbering) enhances the affinity shift from avian to human-like receptors [38]. In this regard, Matrosovich et al. (2008) reported that residue 234L is typical of human pandemics AIV H2 and H3 subtypes. The emergence of additional basic amino acids at the HA cleavage site of the Tunisian AIV (GF/121/14) does not seem to influence the pathogenicity since the intravenous pathogenicity index (IVPI) was 0.50 .

The five strains showed conserved residues with AIV H9N2 isolated from poultry (2012-2016) (P110, W161, T163, H191, A198 and I235) in the receptor-binding pocket for the RBS receptor binding site, except (GF/TN/120/15) and (GF/TN/121/14) that had A198Tsubstitutions, which has been associated with a medium affinity to human receptors [21] and has been classified by Wan et al. This allows H9N2 viruses to preferentially infect non-hair cells and to multiply more efficiently in human respiratory tract epithelial cells with increased severity [38].

The Tunisian wetland (Maamoura lagoon, Korba Lagoon, and Kuriat Island) serves as a major flyway for migrating greater flamingos, which stopover in this region during both their northern and southern migrations. Consequently, Tunisia remains at high risk for potential A/H5N1 introductions. Areas such as Lake Island and lagoons, where wetland birds rest during their migration, might be highly contaminated with AIV from bird feces. The AIV isolates from Maamoura Lagoon water (EN/TN/117/18) had a HA motif different from wild birds sampled in the same lagoon; this could be explained by the presence of other waterfowl not sampled in our study, other species of waterfowl, such as mallard duck and gulls, have been observed during this outbreak at the Maamoura Lagoon.

Water plays a significant role in the spread of pathogenic viruses, such as avian influenza viruses (AIV) [30]. Most of the AIV strains circulating globally replicate in the intestines of birds and have low pathogenicity (LPAI). Occasionally, high pathogenic avian influenza (HPAl) viruses that replicate mainly in the respiratory tract epithelium and other organs of birds can be shed in natural water by infected birds [23]. The survival of AIVs in water depends on recognizing the antigenic site, the $\mathrm{pH}$, the temperature, and the salinity of the water [4]. In general, despite their enveloped structure, they persist especially well in non-saline water with slightly elevated $\mathrm{pH}$ and low temperature.

The mutation in NA created two glycosylation sites inside and near the HB site that might prevent antibodies from binding. Matrosovich et al. reported that two mutations, S372A and R403W, enhanced the cross of the species barrier and the adaptation to a mammalian host. These two mutations were detected in Asia and the Middle East in H2N2 and H3N2 subtypes that caused human pandemics. All of the Tunisian isolates revealed the mutations L370, 1392, and 1427, which provide the ability for H9N2 viruses to replicate in mouse cells without killing them [19]. The five Tunisian H9N2 viruses had the PDZ domain of "K/RSEV" E55 in NS1, which was related to the virulence of the H5N1 strain in mammals and the resistance to cytokines and S42, which can increase the virulence of avian influenza virus in mammalian models [9].

The Tunisian AIV H9N2 viruses accumulated new mutations in NP, M2, and PA, and we identified mammalian host-specific markers in Tunisian H9N2 viruses in M (M1 V15I, M2 G16 and I28) [9], NP (D34G, E372D) [35], PA (409S 262R391K 409V) [17]. Sequence analysis of PB1 also identified markers that increase pathogenicity and virulence in host PB1 (5338D, 578K, 678S) [27]. The PB2 mutation R251K has been associated with increased viral replication, and pathogenicity of H1N1 was detected in this study for one 
strain, (A/GF/120/15) [22]. The PB2 of strains (A/LW117/18) and (A/GHG/216/18) had a new point mutation in its cap-binding site (E249D), and strain (A/GF/120/15) had the E249A mutation. The effects of these substitutions are still unknown.

After inoculation of BALB/c mice, the four viruses [(GF/TN/120/15), (GF/TN/121/14), (GHG/TN/216/18), and (BWS/TN/119/18)] could not kill mice; all viruses merely replicated in the mice. Although many mammalian receptor-binding and host-specific mutations were found in these wild birds' H9N2 viruses, they did not fundamentally change the infectivity and pathogenicity of mammals. Two H9N2 viruses, (GHG/TN/216/18) and (BWS/TN/119/18), were isolated from dead animals. H9N2 viruses (GF/TN/120/15) and (GF/TN/121/14) were isolated from healthy animals during the nesting period, when they can easily make contact with poultry in farms with poor biosecurity measures, and thus potentially spread the viruses. Despite the molecular characters of chicken H9N2 AIV being regularly reported in North Africa, West Africa, H9N2 AIV strains from wild birds werenot characterized. LPAIV in wild birds can evolve into HPAIV once introduced into poultry $[4,15,41]$. Thus, LPAIV circulating in wild birds poses an indirect threat to poultry and public health. It has been reported that $\mathrm{A} / \mathrm{H} 5 \mathrm{~N} 1$ has the potential to be widely introduced into Africa by wild birds migrating from Europe, where A/H5N1 is present [12], and circulated within Africa from countries already experiencing outbreaks. In conclusion, the present study reports, for the first time, the full-length genome sequences of five AIV H9N2 isolated from greater flamingo (GF) (P. roseus), gray-headed gull (GHG) (C. crirrocephalus), black-winged stilt (BWS) (H. himantopus), and lagoon water in Tunisia. Phylogenetic analysis showed that the Tunisian AIV H9N2 from wild birds and environment are grouped with the North African, West African, and Middle Eastern AIV H9N2 chicken strains within the G1 sublineage H9N2. Molecular analysis showed many molecular markers associated with the adaptation of AIV to mammals. These AIV H9N2 had low pathogenicity in chickens, could not kill mice, and merely replicated when administrated to mice. There is a considerable risk that these avian species have been the origin of the introduction of AIV H9N2 in Tunisia and North and West Africa on their arrival during migration, and that these AIVs transmit partially or completely to bird species linked to residues with a more extensive transmission to local manufacturers or domestic birds.

\section{Declarations}

\section{Acknowledgments}

This study was supported by the Research Grant from the Tunisian Ministry of Research and was a part of the research program of the Laboratory of Veterinary Microbiology (Grant reference MEV09). Also, we thank American Manuscript Editors for language editing.

\section{Compliance with ethical standards}

Conflict of interest. The authors declare no conflict of interest.

\section{References}

1. Arbi M, Souiai S, Rego N, Larbi I, Naya H, Ghram A, Houimel M (2020) Historical origins and zoonotic potential of avian influenza virus H9N2 in Tunisia revealed by Bayesian analysis and molecular characterization. Arch Virol 165(7):1527-1540. https://doi.org/10.1007/s00705-020-04624-4

2. Awuni JA, Bianco A, Dogbey OJ, Fusaro A, Yingar DT, Salviato A, Ababio PT, Milani A, Bonfante F, Monne I (2019) Avian influenza H9N2 subtype in Ghana: Virus characterization and evidence of co-infection. Avian Pathol 48:470-476. https://doi.org/10.1080/03079457.2019.1624687

3. Barberis A, Boudaoud A, Gorrill A, Loupias J, Ghram A, Lachheb J, Alloui N, Ducatez MF (2020) Full-length genome sequences of the first H9N2 avian influenza viruses isolated in the Northeast of Algeria. Virology Journal 17:108. https://doi.org/10.1186/s12985-020-01377-z

4. Banks J, Speidel ES, Moore E, Plowright L, Piccirillo A, Capua I, Cordioli P, Fioretti A, Alexander DJ (2001) Changes in the haemagglutinin and the neuraminidase genes prior to the emergence of highly pathogenic H7N1 avian influenza viruses in Italy. Archive of Virology 146:963-973. https://doi.org/10.1007/s007050170128

5. Zecchin B, Minoungou G, Fusaro A, Moctar S, Ouedraogo Kaboré A, Schivo A, Salviato A, Marciano S, Monne I (2017) Influenza A (H9N2) virus, Burkina Faso. Emerg Infect Dis 23:2118-2119. https://doi.org/10.3201/eid2312.171294

Page 10/16 
6. Brown JD, Swayne DE, Cooper RJ, Burns R, Stallknecht DE (2007) Persistence of H5 and H7 avian influenza viruses on water. Avian Dis 50:285-289. https://doi.org/10.1637/7636-042806R.1

7. Chen GW, Chang SC, Mok CK, Lo YL, Kung YN, Huang JH, Shih YH, Wang JY, Chen CJ, Shih SR (2006) Genomic signatures of human versus avian influenza A viruses. Emerg Infect Dis 12:1353-1360. https://doi.org/10.3201/eid1209.060276

8. Bridges CB, Thompson WW, Meltzer MI, Reeve GR, Talamonti WJ, Cox NJ, Lilac HA, Hall H, Klimov A, Fukuda K (2000) Effectiveness and cost-benefit of influenza vaccination of healthy working adults. JAMA284:1655-1663. https://doi.org/10.1001/jama.284.13.1655

9. Dongdong Wang J, Wang Y, Bi, Dandan Fan, Hong Liu, Ning Luo

10. Zongtong Yang S, Wang W, Chen J, Wang S, Xu J, Chen Y, Zhang, Yanbo Yin (2018) Characterization of avian influenza H9N2 viruses isolated from ostriches (Struthiocamelus). Sci Rep 8:2273. https://doi.org/10.1038/s41598-018-20645-1

11. Couacy-Hymann E, Kouakou VA, Aplogan GL, Awoume F, Kouakou CK, Kakpo L, Sharp BR, Mc Clenaghan L, McKenzie P, Webster RG, Webby RJ, Ducatez MF (2012) Surveillance for influenza viruses in poultry and swine, West Africa, 2006-2008. Emerg Infect Dis 18:9. https://doi.org/10.3201/eid1809.111296

12. Gabriel G, Abram M, Keiner B, Wagner R, Klenk HD, Stech J (2007) Differential polymerase activity in avian and mammalian cells determines host range of influenza virus. J Virol 81:9601-9604. https://doi.org/10.1128/JVI.00666-07

13. Gaidet N, Dodman T, Caron A, Balança G, Desvaux S et al (2007) Influenza surveillance in wild birds in Eastern Europe, the Middle East, and Africa: Preliminary results from an ongoing FAO-led survey. J Wildl Dis 43:S22-S28

14. Guan Y, Shortridge KF, Krauss S, Webster RG (1999) Molecular characterization of H9N2 influenza viruses: Were they the donors of the "internal" genes of H5N1 viruses in Hong Kong? PNAS96:9363-9367. https://doi.org/10.1073/pnas.96.16.9363

15. Houadfi ME, Fellahi S, Nassik S, Guérin J-L, Ducatez MF (2016) First outbreaks and phylogenetic analyses of avian influenza H9N2 viruses isolated from poultry flocks in Morocco. Virol J 13:140. https://doi.org/10.1186/s12985-016-0596-1

16. Horimoto T, Murakami S, Muramoto Y, Yamada S, Fujji K, Kiso M, Iwatsuki-Horimoto K, Kino Y, Kawaoka Y (2007) Enhanced growth of seed viruses for H5N1 influenza vaccines. Virology 366:23-27. https://doi.org/10.1016/j.virol.2007.07.002

17. Iqbal M, Yaqub T, Reddy K, McCauley JW (2009) Novel genotypes of H9N2 influenza A viruses isolated from poultry in Pakistan containing NS genes similar to highly pathogenic H7N3 and H5N1 Viruses. PLoS ONE 4:e5788.

https://doi.org/10.1371/journal.pone.0005788

18. Jun Liu F, Huang JsongZLikai, Tan G, Lu Xu, Zhang H, Zhang (2016) Characteristic amino acid changes of influenza A(H1N1) pdm09 virus PA protein enhance A(H7N9) viral polymerase activity. Virus Genes 52:346-353. https://doi.org/10.1007/s11262016-1311-4

19. Kammon A, Heidari A, Dayhum A, Eldaghayes I, Sharif M, Monne I, Cattoli G, Asheg A, Farhat M, Kraim E (2015) Characterization of avian influenza and Newcastle disease viruses from poultry in Libya. Avian Dis Sep 59:422-430. https://doi.org/10.1637/11068-032215-ResNote.1

20. Li C, Yu K, Tian G, Yu D, Liu L, Jing B, Ping J, Chen H (2005) Evolution of H9N2 influenza viruses from domestic poultry in Mainland China. Virology 340:70-83. https://doi.org/10.1016/j.virol.2005.06.025

21. Manual on Animal Influenza Diagnosis and Surveillance from WHO (2002) (World Health Organization)

22. Matrosovich MN, Krauss S, Webster RG (2001) H9N2 influenza A viruses from poultry in Asia have human virus-like receptor specificity. Virology 281:156-162

23. Cai M, Zhong R, Qin C, Yu Z, Wen X,JunsiXian, Chen Y, Cai Yu, Yi H, Lang Gong,Guihong Zhang (2020) The R251K substitution in viral protein pb2 increases viral replication and pathogenicity of Eurasianavian-like H1N1 swine influenza viruses. Viruses 12:52. https://doi.org/10.3390/v12010052

24. Mundt E, Gay L, Jones L, Saavedra G, Tompkins SM, Tripp RA (2009) Replication and pathogenesis associated with H5N1, H5N2, and H5N3 low-pathogenic avian influenza virus infection in chickens and ducks. Arch Virol 154(8):1241-1248. https://doi.org/10.1007/s00705-009-0437-2

25. Muthannan Andavar Ramakrishnan (2016) Determination of 50\% endpoint titer using a simple formula. World J Virol. 12; 5(2): 85-86. https://doi.org/10.5501/wjv.v5.i2.85

26. Naffakh N, Tomoiu A, Rameix-Welti MA, van der Werf S (2008) Host restriction of avian influenza viruses at the level of the ribonucleoproteins. Annu Rev Microbiol 62:403-424. https://doi.org/10.1146/annurev.micro.62.081307.162746

Page $11 / 16$ 
27. Nicholson KG, Wood JM, Zambon M (2003) Influenza. The Lancet 362. https://doi.org/10.1016/S0140-6736(03)14854-4

28. OIE Terrestrial Manuel (2018) Avian Influenza (Infection with Avian Influenza Viruses)

29. Olsen B, Munster VJ, Wallensten A et al (2006) Global trends in influenza A virus in wild birds. Science 312:384-388

30. Pan C, Cheung B, Tan S et al (2010) Genomic signature and mutation trend analysis of pandemic (H1N1) influenza A virus. PLoS ONE 5:e9549. https://doi.org/10.1371/journal.pone.0009549

31. Rohani P, Breban R, Stallknecht DE, Drake JM (2000) Environmental transmission of low pathogenicity avian influenza viruses and its implications for pathogen invasion. PNAS 106:10365-10369. https://doi.org/ 10.1073/pnas.0809026106

32. Salomon R, Webster RG (2009) The influenza virus enigma. Cell 136:402 - 10. https://doi.org/10.1016/j.cell.2009.01.029

33. Shaw M, Cooper L, Xu X, Thompson W, Krauss S, Guan Y, Zhou N, Klimov A, Cox N, Webster R, Lim W, Shortridge K, Subbarao K (2002) Molecular changes associated with the transmission of avian influenza a H5N1 and H9N2 viruses to humans. J Med Virol 66:107-114. https://doi.org/10.1002/jmv.2118

34. Steidle S, Martínez-Sobrido L, Mordstein M, Lienenklaus S, García-Sastre A, Stäheli P, Kochs G (2010) Glycine 184 in nonstructural protein NS1 determines the virulence of influenza A virus strain PR8 without affecting the host interferon response. J Virol 2010 84:12761-127. https://doi.org/ 10.1128/JVI.00701 - 10

35. Stevens KB, Costard S, Métras R, Theuri W, Hendrick S, Pfeiffer DU (2010) Final Report and Risk Maps; Early Detection, Reporting, and Surveillance-Avian Influenza in Africa Project - USAID

36. Jakhesara SJ, Bhatt VD, Patel NV, Prajapati KS, Joshi CG (2014) Isolation and characterization of H9N2 influenza virus isolates from poultry respiratory disease outbreak. Springer Plus 3:196. https://doi.org/10.1186/2193-1801-3-196

37. Wernery U, Shanmuganatham KK, Krylov PS, Joseph S, Friedman K, Krauss S, Webster RG (2013) H9N2 influenza viruses from birds used in falconry. Influenza Other Respir Viruses 7:1241-1245. https://doi.org/ 10.1111/irv.12143

38. Tombari W, Nsiri J, Larbi I, Guerin JL, Ghram A (2011) Genetic evolution of low pathogenicity H9N2 Avian influenza viruses in Tunisia: acquisition of new mutations. Virology Journal 8:467. https://doi.org/10.1186/1743-422X-8-467

39. Wan H, Perez DR (2007) Amino acid 226 in the hemagglutinin of H9N2 influenza viruses determines cell tropism and replication in human airway epithelial cells. J Virol 81:5181-5191. https://doi.org/10.1128/JVI.02827-06

40. Wu R, Sui ZW, Zhang HB, Chen QJ, Liang WW, Yang KL, Xiong Z, Liu ZW, Chen Z, Xu DP (2007) Characterization of a pathogenic H9N2 influenza A virus isolated from central China (2008). Arch Virol 153:1549-1555.

https://doi.org/10.1007/s00705-008-0139-1

41. Wu Y, Wu Y, Tefsen B, Shi Y, Gao GF (2014) Bat-derived influenza-like viruses H17N10 and H18N11. Trends Microbiol 22:183191. https://doi.org/10.1016/j.tim.2014.01.010

42. Xu KM, Smith GJ, Bahl J, Duan L, Tai H et al (2007) The genesis and evolution of H9N2 influenza viruses in poultry from southern China, 2000 to2005.J Virol 81: 10389-10401. https://doi.org/ 10.1128/JVI.00979-07

43. Zhang Z, Hu S, Li Z, Wang X, Liu M, Guo Z, Li S, Xiao Y (2011) Multiple amino acid substitutions involved in enhanced pathogenicity of LPAI H9N2 in mice. Infect Genet Evol 11:1790-1797. https://doi.org/10.1016/j.meegid.2011.07.025 7.

\section{Tables}

Table1: Tunisian H9N2 virus strains.

\begin{tabular}{|llll|}
\hline Virus & Abbreviation & Site of collection & Host \\
\hline A/Greater flamingo/Tunisia/120/2015 & GF/TN/120/15 & Korba Lagoon & greater flamingo \\
\hline A/Greater flamingo/Tunisia/121/2014 & GF/TN/121/14 & Korba Lagoon & greater flamingo \\
\hline A/ Black Winged Stilt /Tunisia/119/2018 & BWS/TN/119/18 & Maamoura Lagoon & black-winged stilt \\
\hline A/Gray headed gull/Tunisia/216/2018 & GHG/TN/216/18 & Kuriat Island & gray-headed gull \\
\hline A/environment/Tunisia/117/2018 & EN/TN/117/18 & Maamoura Lagoon & Environment \\
\hline
\end{tabular}

Table 2. Viral distribution of H9N2 avian influenza in various organs of mice by RT-PCR targeting the M and H9 genes.

Page $12 / 16$ 


\begin{tabular}{|c|c|c|c|c|c|c|c|c|c|c|c|c|}
\hline \multirow{2}{*}{$\begin{array}{l}\text { Strains } \\
\text { Organs }\end{array}$} & \multicolumn{3}{|c|}{ GF/TN/120/15 } & \multicolumn{3}{|c|}{ GF/TN/121/14 } & \multicolumn{3}{|c|}{ GHG/TN/216/18 } & \multicolumn{3}{|c|}{ BWS/TN/119/18 } \\
\hline & dpi3 & dpi6 & dpi8 & dpi3 & dpi6 & dpi8 & dpi3 & dpi6 & dpi8 & dpi3 & dpi6 & dpi8 \\
\hline $\begin{array}{l}\text { Nasal } \\
\text { turbinates }\end{array}$ & $\begin{array}{l}2 / 3 \\
(\mathrm{NM}+)\end{array}$ & $\begin{array}{l}1 / 3 \\
(\mathrm{NM}+)\end{array}$ & $\begin{array}{l}0 / 3 \\
(\mathrm{NM}-)\end{array}$ & $\begin{array}{l}2 / 3 \\
(\mathrm{NM}+)\end{array}$ & $\begin{array}{l}1 / 3 \\
(\mathrm{NM}+)\end{array}$ & $\begin{array}{l}0 / 3 \\
\text { (NM-) }\end{array}$ & $\begin{array}{l}1 / 3 \\
(\mathrm{NM}+)\end{array}$ & $\begin{array}{l}1 / 3 \\
(\mathrm{NM}-)\end{array}$ & $\begin{array}{l}0 / 3 \\
\text { (NM-) }\end{array}$ & $\begin{array}{l}2 / 3 \\
(\mathrm{NM}+)\end{array}$ & $\begin{array}{l}1 / 3 \\
(\mathrm{NM}+)\end{array}$ & $\begin{array}{l}0 / 3 \\
(\mathrm{NM}-)\end{array}$ \\
\hline Trachea & $\begin{array}{l}2 / 3 \\
(\mathrm{NM}+)\end{array}$ & $\begin{array}{l}1 / 3 \\
(\mathrm{NM}+)\end{array}$ & $\begin{array}{l}1 / 3 \\
(\mathrm{NM}+)\end{array}$ & $\begin{array}{l}2 / 3 \\
(\mathrm{NM}+)\end{array}$ & $\begin{array}{l}1 / 3 \\
(\mathrm{NM}+)\end{array}$ & $\begin{array}{l}1 / 3 \\
\text { (NM-) }\end{array}$ & $\begin{array}{l}1 / 3 \\
(\mathrm{NM}+)\end{array}$ & $\begin{array}{l}1 / 3 \\
(\mathrm{SN}-)\end{array}$ & $\begin{array}{l}2 / 3 \\
(\mathrm{NM}-)\end{array}$ & $\begin{array}{l}1 / 3 \\
(\mathrm{SN}+)\end{array}$ & $\begin{array}{l}1 / 3 \\
(\mathrm{NM}+)\end{array}$ & $\begin{array}{l}1 / 3 \\
(\mathrm{NM}+)\end{array}$ \\
\hline Lungs & $\begin{array}{l}2 / 3 \\
(\mathrm{NM}+)\end{array}$ & $\begin{array}{l}3 / 3 \\
(\mathrm{NM}+)\end{array}$ & $\begin{array}{l}2 / 3 \\
(\mathrm{NM}+)\end{array}$ & $\begin{array}{l}2 / 3 \\
(\mathrm{NM}+)\end{array}$ & $\begin{array}{l}1 / 3 \\
(\mathrm{NM}+)\end{array}$ & $\begin{array}{l}2 / 3 \\
(\mathrm{NM}+)\end{array}$ & $\begin{array}{l}3 / 3 \\
(\mathrm{NM}+)\end{array}$ & $\begin{array}{l}3 / 3 \\
(\mathrm{NM}+)\end{array}$ & $\begin{array}{l}2 / 3 \\
(\mathrm{NM}+)\end{array}$ & $\begin{array}{l}1 / 3 \\
(\mathrm{NM}+)\end{array}$ & $\begin{array}{l}3 / 3 \\
(\mathrm{NM}+)\end{array}$ & $\begin{array}{l}2 / 3 \\
(\mathrm{NM}+)\end{array}$ \\
\hline
\end{tabular}

NM: Naive Mice, - Negative,+ Positive, dpi: Day Post Infection

Table 3: Analysis of amino acid sequences of the NA protein compared with those of the gene library.

\begin{tabular}{|llll|}
\hline Isolates & HB active sites & \multicolumn{2}{l|}{ Glycosylation sites } \\
\cline { 2 - 4 } & $366-373$ & $399-406$ & $431-433$ \\
\hline LW/TN/117/18 & IKKDLRA & DSDNWSGY & PKE \\
\hline GHG/TN/216/18 & IKKDLRA & DSDNWSGY & PKE \\
\hline GF/TN/121/14 & IKKDLRA & DSDDWSGY & PKE \\
\hline GF/TN/120/15 & IKKDLRA & DSDDWSGY & PKE \\
\hline BWS/TN/119/18 & IKKDLRA & DSDDWSGY & PKE \\
\hline
\end{tabular}

Table 4: Amino acid analysis in the eight genes of interest. The function of each site is described in brief, together with the related references 


\begin{tabular}{|c|c|c|c|c|c|c|c|}
\hline Protein & Sites & EN/TN & $\mathrm{GHG} / \mathrm{TN}$ & GF/TN & GF/TN & BWS/TN & Function \\
\hline & & $117 / 18$ & $216 / 18$ & $120 / 15$ & $121 / 14$ & $119 / 18$ & \\
\hline \multirow[t]{3}{*}{ HA } & 198 & A & A & $\mathrm{T}$ & $\mathrm{T}$ & $A$ & Situated in RBS \\
\hline & 234 & $\mathrm{~L}$ & L & L & L & L & Confers the ability to bind a2,6 sialic receptors \\
\hline & & & & & & & of human epithelial cells \\
\hline \multirow[t]{5}{*}{ NA } & 72 & $\mathrm{~T}$ & $\mathrm{~T}$ & $\mathrm{~T}$ & $\mathrm{~T}$ & $\mathrm{~T}$ & $\begin{array}{l}\text { Gives H9N2 the ability to replicate in mouse } \\
\text { cells [19] }\end{array}$ \\
\hline & 393 & I & 1 & I & D & I & $\begin{array}{l}\text { Gives H9N2 the ability to replicate in mouse } \\
\text { cells [19] }\end{array}$ \\
\hline & 470 & I & 1 & 1 & I & I & $\begin{array}{l}\text { Gives H9N2 the ability to replicate in mouse } \\
\text { cells [19] }\end{array}$ \\
\hline & 331 & S & $\mathrm{N}$ & $\mathrm{N}$ & $\mathrm{N}$ & $\mathrm{N}$ & $\begin{array}{l}\text { S331N creates the glycosylation site } \\
\text { 331NSS33 }\end{array}$ \\
\hline & 402 & $\mathrm{~N}$ & $\mathrm{~N}$ & $\mathrm{~N}$ & $\mathrm{D}$ & $\mathrm{N}$ & $\begin{array}{l}\text { D } 402 \mathrm{~N} \text { creates the glycosylation site } \\
\text { 402NWS404 }\end{array}$ \\
\hline \multirow[t]{2}{*}{ PB2 } & E249 & D & $\mathrm{D}$ & $A$ & $\mathrm{E}$ & E & Located in the cap-binding region \\
\hline & R251 & $\mathrm{R}$ & $\mathrm{R}$ & $\mathrm{K}$ & $\mathrm{R}$ & $\mathrm{R}$ & $\begin{array}{l}\text { Increase viral replication and pathogenicity of } \\
\text { H1N1 [22] }\end{array}$ \\
\hline \multirow[t]{2}{*}{ PB1 } & D538 & $\mathrm{D}$ & $\mathrm{D}$ & $\mathrm{D}$ & D & $\mathrm{D}$ & Important for virulence and pathogenicity [25] \\
\hline & S678 & S & S & S & S & S & Important for virulence and pathogenicity [25] \\
\hline \multirow[t]{7}{*}{ PA } & $\mathrm{K} 262 \mathrm{R}$ & $\mathrm{R}$ & $\mathrm{R}$ & $\mathrm{K}$ & $\mathrm{K}$ & $\mathrm{R}$ & Could enhance viral fitness in humans [17] \\
\hline & R391K & $\mathrm{R}$ & $\mathrm{R}$ & $\mathrm{K}$ & $\mathrm{K}$ & $\mathrm{R}$ & Could enhance viral fitness in humans [17] \\
\hline & I407V & I & I & V & V & I & Rare amino acid mutation on AIV converting \\
\hline & & & & & & & it to sequence characteristic of H1N1 [17] \\
\hline & S409N & $\mathrm{N}$ & $\mathrm{N}$ & $\mathrm{N}$ & $\mathrm{N}$ & $\mathrm{N}$ & Could enhance viral fitness in humans [17] \\
\hline & L672 & $\mathrm{L}$ & L & L & L & $\mathrm{L}$ & Markers of virulence \\
\hline & L550 & $\mathrm{L}$ & L & L & L & $\mathrm{L}$ & Markers of virulence \\
\hline \multirow[t]{2}{*}{ NP } & M136 & M & M & M & M & M & Markers of human-associated H9 viruses [35] \\
\hline & E392D & $E$ & $\mathrm{D}$ & $E$ & $E$ & $\mathrm{D}$ & Markers of human-associated H9 viruses [35] \\
\hline \multirow[t]{3}{*}{ M1 } & V15I & I & I & I & I & I & Mammalian host-specific markers [9] \\
\hline & N30D & $\mathrm{D}$ & $\mathrm{D}$ & $\mathrm{D}$ & $\mathrm{D}$ & $\mathrm{D}$ & Increased virulence in mice $[9,42]$ \\
\hline & T125A & A & A & A & A & A & Increased virulence in mice $[9,42]$ \\
\hline \multirow[t]{2}{*}{ M2 } & G16 & G & G & G & G & G & Mammalian host-specific markers $[7,32]$ \\
\hline & 128 & I & I & I & I & I & Mammalian host-specific markers $[7,32]$ \\
\hline \multirow[t]{4}{*}{ NS1 } & D55E & $\mathrm{E}$ & $\mathrm{E}$ & $\mathrm{E}$ & $E$ & $\mathrm{E}$ & $\begin{array}{l}\text { Virulence of the H5N1 strain in mammals and } \\
\text { the resistance }\end{array}$ \\
\hline & & & & & & & to cytokines [33] \\
\hline & F103L & $\mathrm{L}$ & L & L & L & L & $\begin{array}{l}\text { Adaptive genetic determinant of growth and } \\
\text { virulence }\end{array}$ \\
\hline & & & & & & & in humans [33] \\
\hline
\end{tabular}




\begin{tabular}{|lllllll|}
\hline G184 & G & G & G & G & G & $\begin{array}{l}\text { Contribute to cleavage and binding to the } \\
\text { specific }\end{array}$ \\
& & & & & polyadenylation factor [33] \\
S42 & S & S & S & S & S & Increased virulence in mammals $[9,42]$ \\
A149 & A & A & A & A & A & Increased virulence in mammals [9,42] \\
\hline
\end{tabular}

\section{Figures}

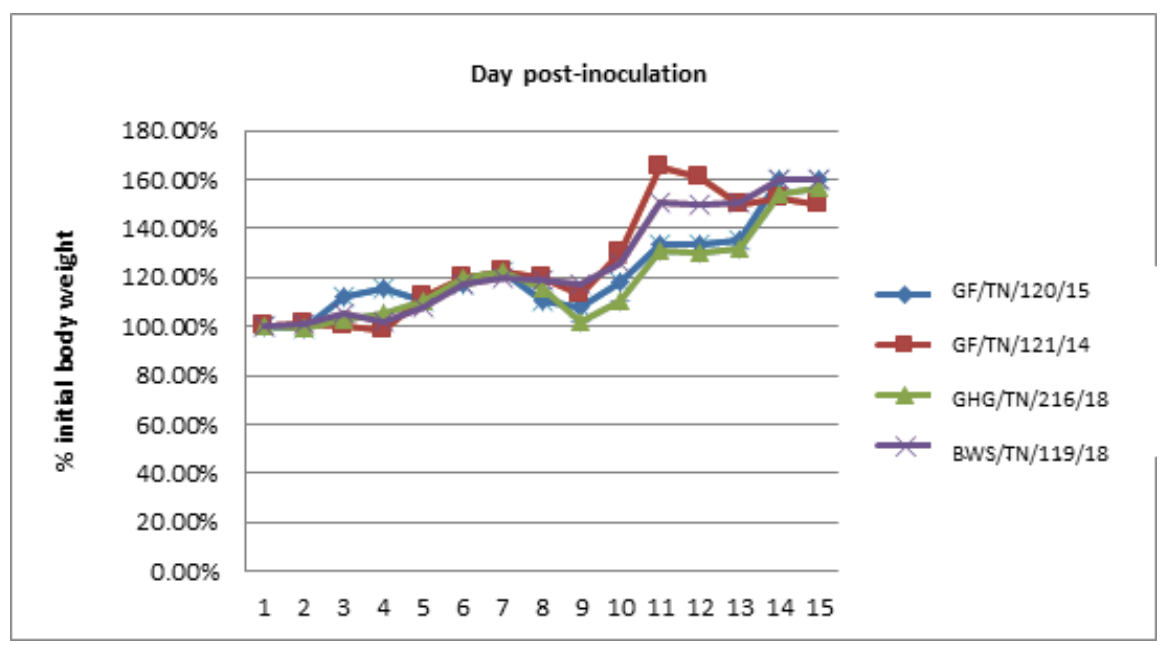

\section{Figure 1}

Mean changes in body weight of mice infected with H9N2 viruses. Mice were inoculated with H9N2 viruses. The body weights were monitored daily for a 14-day observation period and expressed as a percentage of the initial value. 

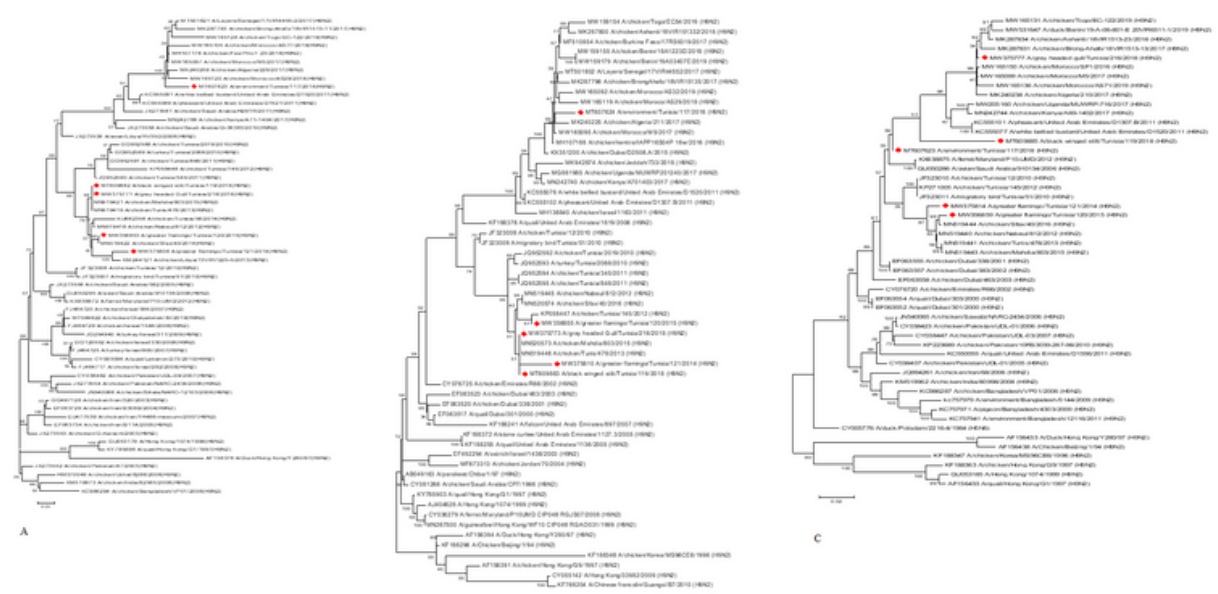

-

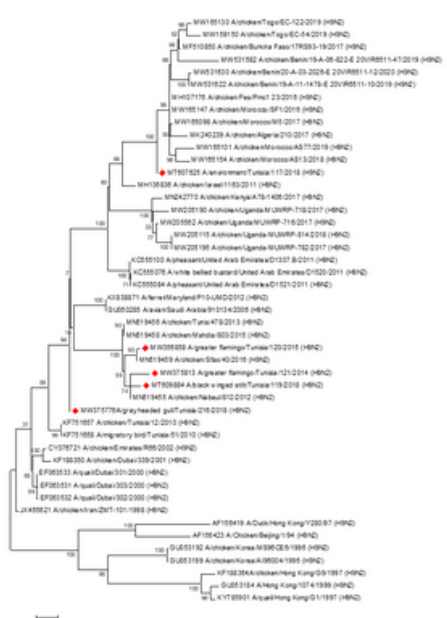

D

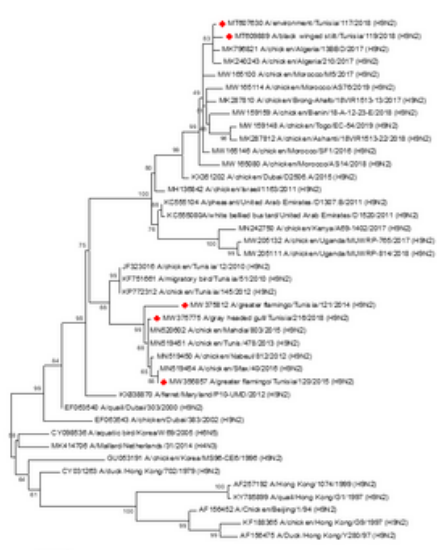

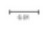
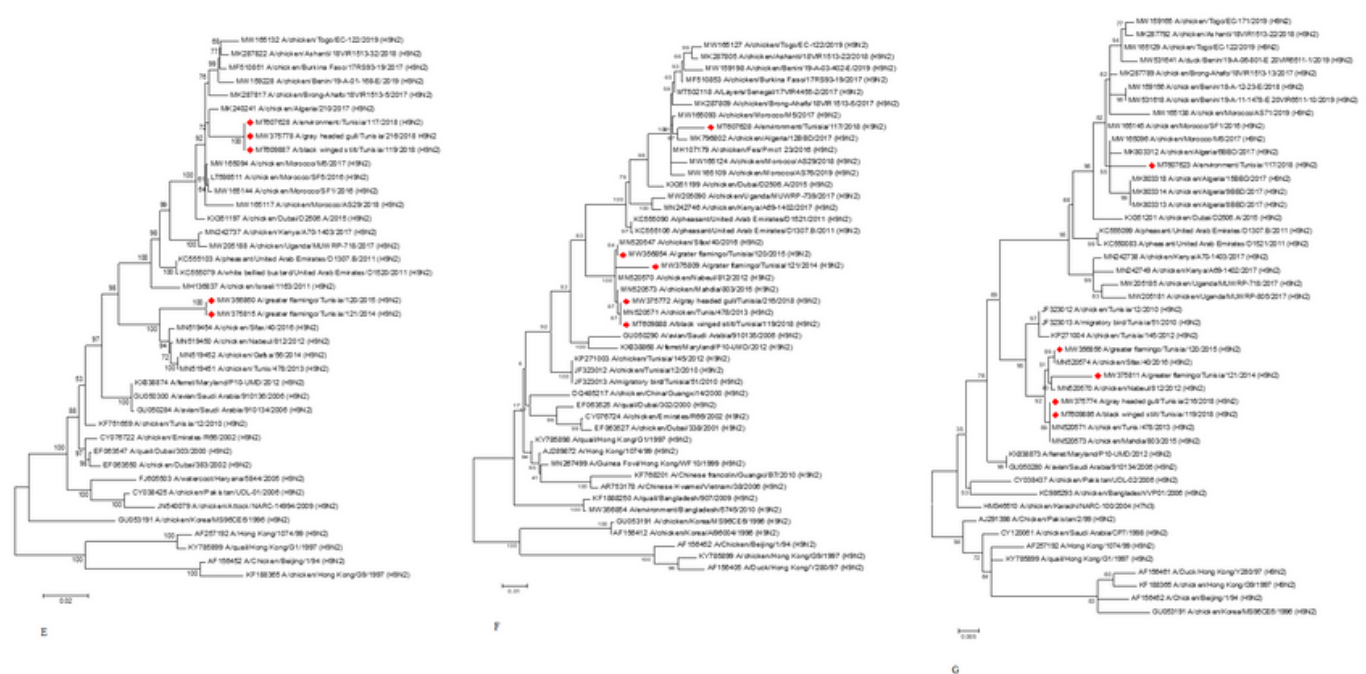

H

\section{Figure 2}

Phylogenetic relationships among the Tunisian H9N2 genes "»" and other H9N2 strains. The HA (A), NA (B), PB2 (C), PB1 (D), PA $(E), N P(F), M(G$,$) and NS (H) genes of the H9N2 viruses were constructed by MEGA using the maximum likelihood method.$ 